HRJ

V.3 n.15 (2022)

Recebido: 14/12/2021

Aceito: 04/01/2022

\title{
Estratégias de enfrentamento da pessoa com doença renal crônica em tratamento hemodialítico
}

\author{
Karen Cruz da Silva ${ }^{1}$ \\ Carmen Lúcia Lucas da Silva ${ }^{2}$
}

\begin{abstract}
${ }^{1}$ Psicóloga Residente do Programa Multiprofissional em Nefrologia da Escola Superior de Ciências e Saúde(ESCS)/ Fundação de Ensino e Pesquisa em Ciências da Saúde (FEPECS)

${ }^{2}$ Mestre em Ciências para a Saúde pela Escola Superior de Ciências e Saúde (ESCS). Psicóloga da Secretaria de Estado de Saúde do Distrito Federal (SES/DF). Preceptora do Programa Multiprofissional em Nefrologia da Escola Superior de Ciências e Saúde (ESCS)/ Fundação de Ensino e Pesquisa em Ciências da Saúde(FEPECS)
\end{abstract}

e-mail para correspondência: karencruzs@outlook.com

\section{RESUMO}

Introdução: A doença renal é considerada um problema de saúde pública, com aumento significativo de pessoas portadoras a cada ano. Um dos tratamentos mais realizados por pessoas com doença crônica terminal é a hemodiálise, procedimento considerado necessário e invasivo. Tanto a doença quanto o tratamento acarretam em mudanças de rotina e vivência das pessoas portadoras de DRC. Objetivo: Identificar quais as estratégias de enfrentamento utilizadas pelas pessoas com doença renal crônica em tratamento hemodialítico. Método: Trata-se de uma pesquisa qualitativa, de caráter exploratório, realizada em um Hospital Regional do Distrito Federal. Para coleta de dados foram utilizados um questionário sociodemográfico e uma entrevista semi estruturada. Resultados: As categorias de análise encontradas foram suporte social; reavaliação positiva; confronto; religiosidade e fuga/esquiva/distanciamento. Conclusão: Os participantes se utilizam de variadas estratégias de enfrentamento, englobando os três tipos de enfrentamento (focado no problema, na emoção e na religiosidade).

Palavras-chave: Insuficiência Renal Crônica; Diálise Renal; Adaptação psicológica.

\section{Coping strategies for people with chronic kidney disease undergoing hemodialysis treatment}

\begin{abstract}
Introduction: Kidney disease is considered a public health problem with a significant increase in carriers every year. One of the most performed procedures by people with a terminal chronic disease is hemodialysis, a method considered necessary and invasive. Both disease and treatment lead to changes in routine and living experience of people with RDC. Objective: To identify the coping strategies used by people with chronic kidney disease undergoing hemodialysis. Method: A qualitative and exploratory research, performed at a
\end{abstract}


Regional Hospital in the Federal District. For data collection, a sociodemographic questionnaire and a semi-structured interview were used. Results: The analysis categories found were social support; positive reappraisal; confrontation; religiosity and escape/avoidance/distancing. Conclusion: Participants use several strategies, encompassing the three types of coping (focused on the problem, emotion and religiosity).

Keywords: Renal Insufficiency, Chronic; Renal Dialysis; Adaptation, Psychological.

\section{INTRODUÇÃO}

A doença renal é considerada um problema de saúde pública devido às elevadas taxas de morbidade e mortalidade decorrentes dela. De acordo com dados da Sociedade Brasileira de Nefrologia, a doença renal crônica tem prevalência no mundo de 7,2\% em indivíduos acima de 30 anos e de $28 \%$ a $46 \%$ em indivíduos acima de 64 anos. Estima-se que no Brasil, cerca de dez milhões de pessoas sejam portadoras da doença, número que nos últimos dez anos cresceram mais de $100 \%^{1,2}$.

A doença renal crônica é uma lesão que afeta os rins e persiste por três meses ou mais, geralmente não aparecendo sinais ou sintomas, especialmente no seu início. Por esse motivo, a melhor forma de prevenção é detectá-la nos seus estágios iniciais. Dentre as suas principais causas estão a hipertensão arterial sistêmica, diabetes mellitus, doenças renais e as uropatias, como infecções urinárias de repetição, obstruções e cálculos renais. Há tratamentos para doença renal e suas causas, bem como para as suas complicações ${ }^{3,4,5}$.

Quando a doença renal crônica atinge estágios avançados, denominado de fase terminal de insuficiência renal crônica, é necessário que a pessoa se submeta a alguma Terapia Renal Substitutiva - TRS, podendo ser: diálise peritoneal, hemodiálise ou transplante renal ${ }^{1,5}$.

Dentre as terapias renais substitutivas, a hemodiálise é a mais empregada. Ela deve ser realizada pelas pessoas portadoras de insuficiência renal crônica sem previsão para interrupção ou até serem submetidas a um transplante renal ${ }^{6 .}$ 
A hemodiálise consiste em um processo no qual os líquidos extra corporais do sangue são filtrados por uma máquina chamada dialisador, que substitui as funções renais, realizando a retirada de líquido, o excesso de sal e toxinas dos resíduos prejudiciais à saúde, ajudando o corpo a manter o equilíbrio de algumas substâncias. Seu principal objetivo é minimizar os sintomas causados pelo mau funcionamento dos rins e proporcionar à pessoa uma melhor qualidade de vida. Os acessos utilizados na hemodiálise são o cateter, fístula arteriovenosa e próteses $^{7,6}$.

A doença crônica é caracterizada como um estado patológico permanente, em que há alterações psicológicas e requer um processo de reabilitação, observação, controle e cuidados. Os indivíduos que vivenciam enfermidades crônicas podem perder vínculos e a sua autonomia, além conviver com o sentimento de medo do futuro pela incapacidade de mudar sua nova condição de saúde ${ }^{4}$.

A pessoa portadora de doença renal crônica em estágios finais se submete a um tratamento doloroso, de longa duração, que acarreta em diversas alterações físicas, emocionais e sociais, culminando em alterações nos seus hábitos de vida e interferindo no papel que essa pessoa desempenha na sociedade. Estudos mostram que a pessoa em tratamento de hemodiálise pode sofrer uma desconexão com o seu mundo, perder o sentimento de indestrutibilidade, a vontade de realizar tarefas e a plenitude de raciocínio ${ }^{8,4,9}$.

Diante das mudanças vivenciadas por pessoas com doença renal crônica, o coping, também conhecido como estratégia de enfrentamento, pode proporcionar uma melhor adaptação do indivíduo a sua nova condição de saúde e vida. As estratégias de enfrentamento são entendidas como habilidades comportamentais e cognitivas utilizadas pelos indivíduos com a finalidade de controlar demandas internas e externas, quando estas são avaliadas como excedentes dos recursos já existentes. As duas principais formas de coping consistem em: enfrentamento focado no problema e enfrentamento focado na emoção ${ }^{10,11}$. 
O enfrentamento focado no problema tem como principal função o gerenciamento ou alteração do evento estressor, sendo mais utilizado quando as consequências desse evento estressor forem identificadas como reversíveis, podendo dessa forma ser removidas ou alteradas. No que se refere ao enfrentamento focado na emoção, a finalidade é de controle, redução ou eliminação das respostas emocionais ao evento estressor, com um aspecto paliativo, visto que o indivíduo busca aliviar o estresse para sentir-se melhor diante de um evento que não pode ser removido ${ }^{11}$.

Além das estratégias de enfrentamento tradicionalmente conhecidas, existe também o coping religioso/espiritual. Esse tipo de enfrentamento é definido como o uso de crenças religiosas para compreender e lidar com os agentes estressores. Existem cinco objetivos principais da religião, sendo eles: busca de significado, de controle, de conforto espiritual, intimidade com Deus e com outros e transformação da vida. Ainda que o conceito de enfrentamento religioso tenha conotação positiva, é importante ressaltar que ele pode ser tanto positivo quanto negativo, à medida que pode proporcionar efeito benéfico ao indivíduo, bem como acarretar em consequências negativas a ele ${ }^{12}$.

O contexto no qual se encontram as pessoas com doença renal crônica, principalmente em tratamento de substituição renal, pode refletir em uma desestruturação de seu cotidiano, representando desafios devido às alterações do seu modo de vida. Além das mudanças físicas e orgânicas, essas pessoas podem passar por significativas mudanças psicossociais, trazendo uma necessidade de explorar a experiência do adoecimento como uma construção social, para além de uma visão biomédica, tradicionalmente seguida por profissionais de saúde ${ }^{13}$.

Considerando que o número de pessoas em tratamento hemodialítico é crescente, que cada pessoa vivencia o processo de adoecimento e o tratamento da sua maneira, que o ser humano deve ser compreendido por uma perspectiva biopsicossocial e que o conhecimento acerca dos enfrentamentos utilizados pelas pessoas com doença renal em tratamento 
hemodialítico é importante para a equipe multidisciplinar no exercício da sua atuação profissional, o objetivo deste artigo é identificar quais as estratégias de enfrentamento utilizadas pelas pessoas com doença renal crônica em tratamento hemodialítico.

\section{MÉTODO}

Trata-se de uma pesquisa qualitativa de cunho exploratório, realizada no setor de Nefrologia de um Hospital Regional do Distrito Federal. Participaram da pesquisa seis pessoas maiores de dezoito anos portadoras de doença renal crônica em tratamento hemodialítico, sendo que todas assinaram o Termo de Consentimento Livre e Esclarecido. Para a coleta de dados foi utilizado um questionário sociodemográfico e uma entrevista semi estruturada confeccionados pela pesquisadora. No que se refere à análise de dados, foi utilizada a Análise de conteúdo temática, metodologia proposta por Bardin. Desta forma, foi realizada uma pré-análise do material coletado, por meio de leitura flutuante, com a finalidade de conhecer os dados. Em seguida, foi realizada a exploração do material, onde foram escolhidas as unidades de categorização das respostas e posteriormente a categorização das respostas, com agrupamento das falas que possuíam o mesmo sentido e/ou temática. Por fim, foi realizada a análise das categorias definidas, com interpretação do conteúdo e sentido encontrado nelas.

O presente estudo, de CAAE n³6818620.9.0000.5553, foi submetido à apreciação do Comitê de Ética em Pesquisa, tendo sido aprovado sob parecer $n^{\circ} 4.250 .307$, em setembro de 2020.

\section{RESULTADOS}

A seguir, a Tabela 1, apresenta os dados sociodemográficos dos participantes. 
Tabela 1 - Dados Sociodemográficos dos participantes. Brasília-DF, Brasil, 2020.

$\begin{array}{ccccccc}\text { Sexo Idade } & \text { Estado } & \text { Tempo } & \text { Comorbidades } & \text { Renda } & \text { Escolaridade } & \text { Religião } \\ & \text { Civil } & \text { de HD } & & & & \end{array}$

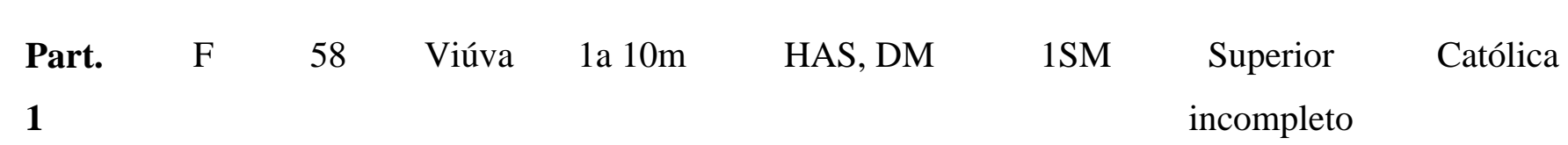

$\begin{array}{llcccccc}\text { Part. } & \text { M } & 57 & \text { União } & \text { 8a } & \text { HAS, HIV } & 2 \mathrm{SM} & \begin{array}{c}\text { Fundamental } \\ \text { Evangélico }\end{array} \\ 2 & & & \text { Estável } & & & \text { incompleto }\end{array}$

\begin{tabular}{|c|c|c|c|c|c|c|c|c|}
\hline Part. & $\mathrm{M}$ & 66 & Solteiro & $4 m$ & HAS, DM & $1 \mathrm{SM}$ & $\begin{array}{c}\text { Fundamental } \\
\text { incompleto }\end{array}$ & Evangélico \\
\hline
\end{tabular}

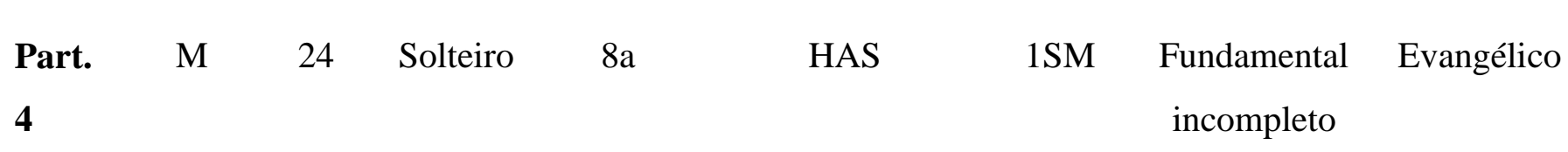

\begin{tabular}{|c|c|c|c|c|c|c|c|c|}
\hline $\begin{array}{l}\text { Part. } \\
5\end{array}$ & $\mathrm{~F}$ & 65 & Solteira & $2 \mathrm{a}$ & HAS & $1 \mathrm{SM}$ & $\begin{array}{l}\text { Superior } \\
\text { incompleto }\end{array}$ & Evangélico \\
\hline $\begin{array}{l}\text { Part. } \\
6\end{array}$ & M & 63 & Solteiro & $21 \mathrm{a}$ & HAS & $1 \mathrm{SM}$ & $\begin{array}{l}\text { Ensino } \\
\text { Médio }\end{array}$ & Não tem \\
\hline
\end{tabular}

Considerando os dados sociodemográficos coletados, como resultado tem-se que em relação ao sexo dos participantes, quatro são do sexo masculino e dois do sexo feminino. A média de idade dos participantes é de 55 anos, sendo os extremos 23 e 65 anos. No que se referem ao estado civil, quatro participantes são solteiros, um viúvo e um está em união estável. A média de tempo de tratamento dialítico dos pacientes é de seis anos e sete meses. Todos os pacientes apresentam como comorbidade Hipertensão Arterial Sistêmica - HAS, 
dois apresentam ainda diagnóstico de Diabetes Mellitus - DM e um apresenta diagnóstico de Vírus da Imunodeficiência Humana - HIV. A renda média dos participantes é de um salário mínimo, sendo que apenas um dos participantes possui renda de dois salários mínimos. No que se refere à fonte de renda pessoal, três participantes são aposentados e três recebem Benefício de Prestação Continuada - BPC e no momento da coleta de dados, apenas um estava ativo no mercado de trabalho e na modalidade informal. No que se referem à escolaridade, três participantes possuem ensino fundamental incompleto, um com ensino médio completo e dois com ensino superior incompleto. No que tange à religião, quatro participantes são evangélicos, um católico e um refere não seguir uma religião específica.

A Tabela 2 identifica o local de moradia dos participantes, bem como com quem eles residem.

Tabela 2. Local de moradia e com quem reside, Brasília-DF, Brasil, 2020.

Participantes

Part. 1

Part. 2

\section{Com quem reside}

Taguatinga - DF Filho
Part. 3
Taguatinga $-\mathrm{DF}$
Filha

Part. 4 Riacho Fundo - DF Sozinho

Part. 5 Recanto das Emas - DF Irmão e cunhada

$\begin{array}{lll}\text { Part. } 6 & \text { Taguatinga - DF Sozinho }\end{array}$ 
A Tabela 2 mostra que todos os participantes residem em cidades satélites do Distrito Federal. Dois dos participantes residem com um filho, dois residem sozinhos, um reside com a companheira e uma filha, e um reside com o irmão e a cunhada.

No que diz respeito à análise de conteúdo realizada a partir das entrevistas, foram encontradas cinco categorias de análise, sendo elas: suporte social; reavaliação positiva; confronto; religiosidade; e fuga/esquiva/distanciamento.

\section{DISCUSSÃO}

Os resultados encontrados evidenciam que os participantes da pesquisa se utilizam de variadas estratégias de enfrentamento frente ao tratamento que realizam. De acordo com estudos, por mais que as estratégias de enfrentamento tenham finalidades distintas, elas podem se interrelacionar, considerando que as pessoas podem se utilizar de ambas as estratégias diante de um evento estressor. Desta forma, mesmo que uma estratégia de enfrentamento esteja em princípio com um foco definido, ela pode se direcionar para outro foco, em uma relação com dinamicidade ${ }^{14,11}$. É importante ressaltar que tanto os estressores quanto às estratégias de enfrentamento variam de acordo com a avaliação individual de cada pessoa, bem como da relação que a mesma tem com o ambiente externo ${ }^{15}$. Desta forma, os participantes apresentam os três grupos de enfrentamento: focado no problema, focado na emoção e focado na religiosidade.

Abaixo, estão descritas as categorias de análise identificadas na pesquisa, que compõem os grupos de enfrentamento supracitados.

\section{Categoria 1: Suporte social}

O suporte social enquanto estratégia de enfrentamento é entendida como estratégias que estão relacionadas ao apoio encontrado, tanto nas pessoas, quanto no ambiente, e apresentam três aspectos diferentes: a procura de apoio social para encontrar soluções; o 
apoio emocional em amigos e familiares e o apoio de profissionais. Além disso, outro fator relevante são os esforços da pessoa na busca de informações ${ }^{14}$. A seguir, encontram-se falas dos participantes referentes ao relacionamento com a equipe de saúde.

(Part. 1) eu gosto de todo mundo, me dou bem com todo mundo, me tratam muito bem. Todos, médicos, enfermeiros, técnico. Isso ajuda, dá um bem estar enorme e uma segurança pra você que é paciente, porque se sente acolhido e acho muito importante. Não é aquele relacionamento distante, eu me sinto muito acolhida.

(Part. 2) Todo mundo é legal, gosto muito. Faz diferença, é bom a gente gostar do lugar, do ambiente, sendo bem tratado, é bom demais. É ruim ficar num lugar que você é maltratado. (Part. 6) relação boa com a equipe ajuda. Já acompanhei muitas pessoas revoltadas que maltratam até os profissionais.

A partir das falas apresentadas acima, pode-se perceber que a relação com a equipe de saúde que presta assistência direta aos pacientes é um recurso de enfrentamento ao tratamento hemodialítico. Os participantes destacam o apoio emocional nos profissionais de saúde que estão com eles no dia a dia do tratamento, enfatizando a importância de serem bem tratados pela equipe e conseguirem ter uma comunicação efetiva com a mesma. Nas falas fica evidente que a busca maior em terceiros está relacionada ao apoio emocional e não foram observadas busca de soluções junto a terceiros ou mesmo busca de informações a respeito do tratamento e seus desdobramentos.

No que se referem ao suporte familiar, estudos apontam que familiares de pessoas com doenças crônicas enfrentam situações de conflito e desgaste, que gera diversos sentimentos, como ansiedade, depressão, tristeza, raiva, medo, dentre outros. Desta forma, a relação familiar pode sofrer abalo em virtude desses sentimentos e causar algum tipo de desordem, ou os vínculos familiares podem ser fortalecidos diante do adoecimento crônico e tratamento. Assim, o abalo ou fortalecimento dos laços familiares terão influência pelas 
condutas dos membros da família, havendo a possibilidade de superar as dificuldades encontradas ou de ser afetado por elas ${ }^{16,17}$. A seguir, o relato dos participantes sobre a relação com a família após início do tratamento.

Part. 1: (relação com a família) Hoje, graças a deus, muito boa. Eu diria que maravilhosa. Assim, em termos de atenção deles para comigo, a hemodiálise ajudou a aproximar meus filhos de mim.

Part. 2: relação com a família é muito boa, todo mundo gosta de mim, pessoal vão lá em casa, a gente conversa e tudo, meus irmãos, os irmãos da mulher. Não me abandonaram em nada. Continuou boa do mesmo jeito depois da hemodiálise.

Part. 3: (relação com a família) graças a Deus muito boa. A diferença sempre surge, você não é mais aquela pessoa normal. mas é tudo bem. Continua igual antes.

A partir das falas acima, é possível identificar que o suporte familiar e a relação familiar saudável se mantiveram após o início do tratamento, sem prejuízos significativos. A fala do participante 1 demonstra que após o início do tratamento, houve uma maior aproximação com os filhos, com ênfase na melhora da relação. Já os participantes 2 e 3, relatam que não houve diferenças a nível relacional e de preocupação, pontuando que a relação com os familiares permanece satisfatória da mesma forma que era anterior ao tratamento. Deste modo, é evidente que a forma com que as relações familiares se moldam após o adoecimento e tratamento de uma pessoa com doença crônica varia de acordo com cada grupo familiar, bem com as condições emocionais e de enfrentamento que cada um possui.

O apoio familiar deve ser considerado pela equipe de saúde como um fator importante na assistência à pessoa com doença renal crônica. Ao passo em que o paciente lida a doença e o tratamento, a família tem a possibilidade de evitar e/ou aliviar situações estressoras, 
amenizando o impacto que o tratamento dialítico gera e possibilitando que o paciente tenha outra perspectiva acerca da sua nova vida, bem como da qualidade dela ${ }^{18}$.

É importante ressaltar que o suporte social pode ser entendido tanto como um enfrentamento focado na emoção, quanto focado no problema, a depender da finalidade para qual é utilizado. Nas falas apresentadas pelos participantes, conclui-se que a finalidade deles está mais ligada a busca por suporte emocional que uma busca de eliminação de eventos estressores, podendo ser caracterizada como enfrentamento focado na emoção.

\section{Categoria 2: Reavaliação positiva}

Essa forma de enfrentamento descreve os esforços dos indivíduos para criar um significado positivo, focando no crescimento pessoal. Observa-se a necessidade do indivíduo em reestruturar o acontecimento, encontrar aspectos favoráveis, dizer coisas a si mesmo para diminuir a gravidade da situação e concentrar-se em pontos positivos da situação, com a

finalidade de amenizar a carga emotiva do acontecimento e tentar modificar a situação ${ }^{14,19}$. A seguir, observam-se falas dos participantes referentes a essa forma de enfrentamento.

(Part. 1) eu me sinto uma vitoriosa, porque depois de tudo que eu passei, meu filho mais velho, por exemplo, achava que eu não ia conseguir voltar a andar, fazer as coisas sozinha, então eu me sinto uma vitoriosa. E veio a aceitação da hemodiálise que me ajudou demais.

(Part. 6) Ou eu fazia hemodiálise ou eu morria. Internei nesse hospital e já passaram o cateter. Depois de mais ou menos 10 anos no morre ou não morre, eu já sabendo que ia morrer, então fazer hemodiálise foi uma vitória, porque não morri e consegui sobreviver, foi uma nova oportunidade de vida e já estou nela há 21 anos.

(Part. 6) se eu levar em consideração os outros e eu, não tenho dificuldade nenhuma. Levo isso aqui numa boa.

(Part. 1) (...) a dificuldade com relação ao tratamento eu não tenho, eu acho que tudo teve o ponto de partida da aceitação. Enquanto eu não aceitava eu passava mal, ficava com 
ansiedade no dia da hemodiálise, era horrível, antes, durante e depois. A partir do momento que eu aceitei, melhorou muito. Não considero ter problemas (com o tratamento).

(Part. 2) Eu primeiramente tive problema de pressão alta, fui internado, quando acordei tava com o cateter no pescoço, ai o médico falou com a mulher lá, que eu ia ficar pouco tempo fazendo isso ai, tudo bem, ai fiz lá meio assim, fiquei né, tô aí até hoje. Mas eu me sinto bem, no começo foi ruim, mas agora eu já me acostumei.

Nas falas acima é possível identificar que os participantes buscaram focar em aspectos positivos do tratamento, seja por meio de comparação da própria experiência no início do tratamento e o momento atual, por comparação com outras pessoas que realizam o mesmo tratamento ou identificação dos prós e contras do tratamento. A fala do participante 6 evidencia que o mesmo compreendeu o tratamento enquanto uma nova oportunidade de vida, considerando o seu estado de saúde anterior e a necessidade da hemodiálise, ao invés de pensar o tratamento enquanto algo negativo e prejudicial a algum âmbito de sua vida.

Os participantes 1 e 2 descrevem a compreensão da hemodiálise como algo positivo para eles enquanto um processo, enfatizando dificuldades no início do tratamento e que com o passar do tempo foram mudando sua percepção frente a ele, passando a ressignificá-lo, seja acostumando-se com ele ou aceitando-o, juntamente com as mudanças decorrentes dele.

As falas mostram pontos opostos no que se refere ao início do tratamento, visto que um dos participantes desde o momento anterior ao início da primeira sessão de hemodiálise já a encarava enquanto algo positivo, necessário e uma nova chance de viver, ao passo em que os outros participantes mostram que tiveram essa percepção apenas após algum tempo de vivência no tratamento e em suas novas rotinas.

$\mathrm{Na}$ literatura existe divergência na categorização da reavaliação positiva. Lazarus e Folkman classificam a reavaliação positiva como um enfrentamento focado na emoção, enquanto Draigle e Stewart a classificam como um enfrentamento focado no problema ${ }^{15}$. 


\section{Categoria 3: Confronto}

Aqui, descrevem-se os esforços para alterar a situação estressante. Faz parte das estratégias ofensivas perante o enfrentamento da situação, ou seja, são atitudes que a pessoa apresenta em relação ao estressor ${ }^{14,19 .}$

(Part. 2) (...) olha, agora minha maior dificuldade é vir pra cá né. Eu estava indo e vindo de ônibus, aí levei uma queda e fui atrás de conseguir o transporte. A dificuldade era essa, agora melhorou mais porque o transporte me pega em casa e me deixa aqui.

(Part. 2) (...) vinha mesmo assim, mesmo com dificuldade. Eu não poderia deixar de fazer o meu tratamento. Diziam que quem faz hemodiálise morre logo, mas quem não faz morre também, então eu vou fazer.

(Part. 4) (...) às vezes estou agoniado, não to com cabeça ... mas ainda assim eu ainda venho.

(Part. 1) (...) o compromisso de vir aqui, segunda, quarta e sexta, por 4 horas, eu tô encarando muito bem. (...) É um compromisso e eu não posso falhar.

Nas falas apresentadas acima, é possível perceber que os participantes entraram em contato de forma direta com os eventos estressantes aos quais estavam expostos, ou buscando soluções para eliminá-los, em casos que tinham resoluções mais práticas, ou vivenciando a situação apesar de ser desgastante e estressora. A fala do participante 2 indica que o fator estressor para ele era o meio de locomoção até o centro de diálise, por haver dificuldades no trajeto, mas que mesmo diante do estressor, o participante o confrontava ao continuar comparecendo ao centro dialisador para realizar o seu tratamento e buscou alternativas viáveis para a eliminação do evento estressor, resultando na concessão de transporte. $\mathrm{O}$ participante 2 apresenta ainda, confronto frente ao tratamento que na concepção de senso comum acelera o processo de morte, entendendo que seria necessário realizá-lo por mais estressor que fosse e mesmo diante dos riscos elencados pelo senso comum. 
Já os participantes 1 e 4, encararam o tratamento enquanto um compromisso que tem que ser cumprido, entrando em contato com ele e realizando-o por mais que a situação em si seja uma fonte de estresse para eles.

\section{Categoria 4: Religiosidade}

O coping religioso pode ser definido como o uso de crenças e/ou comportamentos religiosos que tem como finalidade facilitar a resolução de problemas e prevenir ou aliviar consequências emocionais negativas advindas de situações de vida estressantes ${ }^{20}$.

(Part. 2) (...) Deus quer assim... eu já acostumei, A gente acostuma com o que é ruim também.

(Part. 4) (sobre o diagnóstico) É espiritual. Deu causa desconhecida e revelou na igreja também.

(Part. 5) (rotina após o tratamento) não é normal, mas tô tranquila, sigo um deus vivo que me dá graça. (...) vou para a igreja, leio a bíblia, assisto televisão, louvores.

(Part. 5) (lidar com as dificuldades) eu oro, leio a bíblia, creio em Deus.

O apego a crenças religiosas pode auxiliar no enfrentamento a enfermidades e a tratamentos. Algumas pessoas utilizam-se de suas crenças como uma espécie de válvula de escape, pois a crença em um ser superior os tornam mais preparados para lidar com o tratamento e com os ônus advindos da doença. De acordo com estudos, indivíduos que possuem alguma religião ou crença demonstram menos dificuldades no enfrentamento da doença renal que indivíduos que alegam não possuir qualquer tipo de religião ${ }^{18}$. A religião pode ter caráter negativo e/ou disfuncional na saúde quando crenças ou práticas religiosas são usadas como justificativa para comportamentos com impactos negativos na saúde ou para substituir cuidados médicos tradicionais necessários para o tratamento ou prevenção de alguma doença ${ }^{20}$. 
Todas as falas dos participantes apontam a religião/crença como algo que auxilia na vivência do tratamento, partindo do princípio que há algo maior do que a capacidade humana pode alcançar, acreditando que passar por esse processo de tratamento faça de parte um plano superior. Nenhuma das falas traz conteúdo de perspectiva de cura por seres divinos, bem como riscos de abandonar o tratamento disponível esperando por essa cura. Desta forma, a fé professada pelos participantes pode ser entendida como uma estratégia de enfrentamento funcional, visto que a mesma não causa prejuízo à saúde deles e do tratamento, ao mesmo tempo em que propicia conforto e esperança para eles.

\section{Categoria 5: Fuga/esquiva/distanciamento}

A forma de enfrentamento de afastamento corresponde a estratégias defensivas, ou seja, o indivíduo evita o confronto com aquilo que o ameaça, não sendo possível modificar a situação. Os modos de enfrentamento de fuga-esquiva envolvem o ato de fantasiar sobre possíveis soluções para o problema, mas não realizar ações para modificá-los. Sendo assim, podem ser descritas como desejos, pensamentos e esforços comportamentais para fugir ou anular o problema ${ }^{14,21}$.

(Part. 3) (...) Eu não tenho nada a fazer. só esperar a hora de vir e voltar. Esperar pra ver se tem uma reação, não sei se meu rim vai melhorar ou vou ficar aqui pra sempre. Às vezes dou uma cochilada, às vezes alguém me liga.

(Part. 4) (tempo de tratamento) Eu não conto não. Mas já tem uns 8 anos. Comecei em 2012.

(Part. 3) (sobre o diagnóstico) não, eu não sei, você acredita? Acredito que seja crônico, pelo o que eu vejo falar.

As falas dos participantes acima indicam fuga/esquiva e distanciamento no que refere a assuntos relacionados ao tratamento. $\mathrm{O}$ fato de não contar a quanto tempo realiza o tratamento ou não saber qual é o seu diagnóstico mesmo após já estar há meses em 
tratamento e ter sido informado sobre ele é um indício que os indivíduos não querem entrar em contato com questões que reforçam a continuidade do tratamento e a não interrupção dele.

Diante do adoecimento e tratamento, a aceitação da condição de saúde torna-se mais difícil para o indivíduo, logo, nessas situações ele pode ser induzido a buscar mecanismos de defesa, como a esquiva e a negação. Considerando que a doença renal crônica em conjunto com o tratamento hemodialítico acarretam em restrições significativas à manutenção da qualidade de vida, a negação da própria doença e da necessidade do tratamento se torna uma opção de enfrentamento encontrada ${ }^{18 .}$

Esse tipo de enfrentamento é caracterizado como enfrentamento focado na emoção. Alguns autores acreditam que os modos de enfrentamento focado na emoção são menos efetivos para a criação de estratégias que o enfrentamento focado no problema ${ }^{20,15}$. Apesar do caráter evitativo do enfrentamento apresentado na fala dos participantes 3 e 4, considerando o contexto vivenciado por eles no momento, não há indícios que cause prejuízos frente à saúde, visto que ambos continuam realizando o tratamento conforme o necessário e orientado pela equipe de saúde.

\section{CONCLUSÃO}

Considera-se que o presente estudo atingiu seu objetivo, pois se constatou que pessoas com doença renal crônica em tratamento hemodialítico se utilizam das três formas de enfrentamento amplamente conhecidas na literatura, sendo elas: enfrentamento focado no problema, enfrentamento focado na emoção e enfrentamento religioso; seja de forma individual ou uma junção delas, visto que uma forma de enfrentamento não exclui outra. Desta forma, evidencia-se que a forma como os portadores de DRC em hemodiálise vivenciam o tratamento e o percebem, varia de indivíduo para indivíduo, considerando os elementos internos que cada um tem para lidar a situação, bem como os fatores externos a qual estão em contato direto e/ou indireto. Todas as formas de enfrentamento encontradas no 
estudo mostram-se importantes e efetivas frente à vivência do tratamento, não tendo predominância de importância entre elas.

Destaca-se a importância do estudo a carater de conhecimento, visto que à medida que as equipes de saúde têm ciência dos tipos de estratégias de enfrentamento utilizado por pessoas em tratamento hemodialítico, tem-se uma melhor base para ajustar a assistência direta e indireta a eles de acordo com suas necessidades e especificidades.

No que se refere às limitações do estudo, destaca-se os instrumentos utilizados e o tempo para confecção do mesmo, podendo em outros estudos com a mesma temática utilizar outros instrumentos de coleta de dados e um período mais extenso para o desenvolvimento. Considerando a relevância do tema, espera-se que esse trabalho contribua para a realização de novas pesquisas na área.

\section{REFERÊNCIAS}

1. Martins MRI, Cesarino CB. Qualidade de vida de pessoas com doença renal crônica em tratamento hemodialítico. Revista Latino-Americana de Enfermagem [online]. 2005, v. 13, n. 5, pp. 670-676. Disponível em: 〈https://doi.org/10.1590/S0104-11692005000500010>

2. Biblioteca Virtual em Saúde. Ministério da saúde. 14/3 - Dia Mundial do Rim 2019: Saúde dos Rins Para Todos. Disponível em: <http://bvsms.saude.gov.br/ultimas-noticias/2913-14-3dia-mundial-do-rim-2019-saude-dos-rins-paratodos\#: :text=Segundo $\% 20$ dados $\% 20$ da $\% 20$ Sociedade $\% 20$ Brasileira,de $\% 20$ pessoas $\% 20$ tenh am\%20a\%20doen\%C3\%A7a.> acesso em 15 de junho de 2020.

3. Bastos MG, Bregman R, Kirsztajn GM. Doença renal crônica: frequente e grave, mas também prevenível e tratável. Rev. Assoc. Med. Bras., São Paulo, v. 56, n. 2, p. 248-253, 2010. https://doi.org/10.1590/S0104-42302010000200028 
4. Rudnick T. Doença renal crônica: vivência do paciente em tratamento de hemodiálise. Contextos Clínicos, v. 7, n. 1, p. 105-116, 2014. Disponível em: <http://revistas.unisinos.br/index.php/contextosclinicos/article/view/ctc.2014.71.10/4>

5. Sociedade Brasileira de Nefrologia. Doença renal crônica: diagnóstico e prevenção. Disponível em: <https://www.sbn.org.br/noticias/single/news/doenca-renal-cronicadiagnostico-e-prevencao/> acesso em 20 de junho de 2020.

6. Machado GRG, Pinhati FR. Tratamento de diálise em pacientes com insuficiência renal crônica. Cadernos UniFOA. [Internet] 2014; 9(26): 137-148. Disponível em: http://web.unifoa.edu.br/cadernos/edicao/26/137-148.pdf

7. Gomes KTM. Representações sociais dos acessos para hemodiálise: autopercepção do paciente com doença renal crônica. 2010. 65 f. Trabalho de Conclusão de Curso (Bacharelado em Enfermagem) - Faculdade Nova Esperança de Mossoró, Mossoró. Disponível em: http://www.sistemasfacenern.com.br/repositorio/admin/acervo/7bd4843e404b7a7110066cbc1 3a256e0.pdf. Acesso em 08 de setembro de 2020.

8. Coutinho NPS, Vasconcelos GM, Lopes MLH, Wadle WCA, Tavares MCH. Qualidade de vida de pacientes renais crônicos em hemodiálise. Rev Pesq Saúde. [Internet] 2010; 11(1). Disponível em: http://www.periodicoseletronicos. ufma.br/index.php/revistahuufma/article/view/328, acesso em 24 maio 2020.

9. Souza FTZ, Oliveira JHA. Sintomas depressivos e ansiosos no paciente renal crônico em tratamento conservador. Rev. Psicol. Saúde, Campo Grande, v. 9, n. 3, p. 17-31, dez. 2017. http://dx.doi.org/10.20435/pssa.v9i3.429

10. Fernandes G, Inocente NJ. Estratégias para enfrentamento (coping): um levantamento bibliográfico. In: Encontro Latino Americano de Iniciação Científica, XIV, 2010, Universidade do Vale do Paraíba, São José dos Campos - SP. Disponível em 
http://www.inicepg.univap.br/cd/INIC_2010/anais/arquivos/0570_0609_01.pdf, acesso em 05 de dezembro de 2021.

11. Silva RAR, Neto VLS, Oliveira GFN, Silva BCO, Rocha CCT, Holanda JRR. Estratégias de enfrentamento utilizadas por pacientes renais crônicos em tratamento hemodialítico. Esc. Anna Nery, Rio de Janeiro, v. 20, n. 1, p. 147-154, Mar. 2016. http://dx.doi.org/10.5935/1414-8145.20160020.

12. Valcanti CC, Chaves ECL, Mesquita AC, Nogueira DA, Carvalho EC. Coping religioso/espiritual em pessoas com doença renal crônica em tratamento hemodialítico. Rev. esc. enferm. USP, São Paulo, v. 46, n. 4, p. 838-845, Aug. 2012. https://doi.org/10.1590/S0080-62342012000400008

13. Cavalcante MCV, Lamy ZC, Santos EC, Costa JM. Portadores de doença renal crônica em fase produtiva: percepção sobre limitações resultantes do adoecimento. Rev Med Minas Gerais [Internet]. 2015; [cited 2020 Jun 13]; 25(4): 484-92. DOI: 10.5935/22383182.20150112

14. Bertolin DC, Pace AE, Kusumota L, Haas V. Associação entre os modos de enfrentamento e as variáveis sociodemográficas de pessoas em hemodiálise crônica. Revista da Escola de Enfermagem da USP, 45(5), 1070-6. 2011. doi: 10.1590/S008062342011000500006

15. Bertolin DC. Modos de enfrentamento de pessoas com insuficiência renal crônica terminal em tratamento hemodialítico [dissertação]. Ribeirão Preto: Universidade de São Paulo, Escola de Enfermagem de Ribeirão Preto; 2007 [citado 2021-11-24]. doi:10.11606/D.22.2007.tde-19102007-115608.

16. Oliveira VA, Schwartzb, Soares MC, Santos BP, Garcia RP, Lisef. F. Relações familiares de mulheres em hemodiálise. Rev. Aten. Saúde., São Caetano do Sul, v. 14, n. 47, p. 36-42, jan./mar., $2016 . \quad$ Disponível em: 
http://seer.uscs.edu.br/index.php/revista_ciencias_saude/article/view/3283/pdf, acesso 10 de outubro de 2021

17. Feijó AM, Schwartz E, Jardim VMR, Linck CL, Zillmer JGV, Lange C. O papel da família sob a ótica da mulher acometida por câncer de mama. Cienc cuid saude. $2009 ; 8: 79-84$.

18. Silva RAR, Neto VLS, Oliveira GFN, Silva BCO, Rocha CCT, Holanda JRR. Estratégias de enfrentamento utilizadas por pacientes renais crônicos em tratamento hemodialítico. Escola Anna Nery [online]. 2016, v. 20, n. 1 [Acessado 15 Novembro 2021] , pp. 147-154. DOI: https://doi.org/10.5935/1414-8145.20160020.

19. Marques FRB, Botelho MR, Matos PCB, Puplim JSL, Borelli SD. Hemodiálise: Criando estratégias para enfrentá-la. In: VII EPCC - Encontro Internacional de Produção Científica, 2011, Maringá. VII EPCC - Encontro Internacional de Produção Científica. Maringá: CESUMAR, 2011. v. 1. Disponível em http://www.cesumar.br/prppge/pesquisa/epcc2011/anais/fernanda_ribeiro_baptista_marques $\% 20(2)$.pdf., acesso em 20 de novembro de 2021.

20. Panzini RG, Bandeira DR. Coping (enfrentamento) religioso/espiritual. Archives of Clinical Psychiatry (São Paulo) [online]. 2007, v. 34, suppl 1 [Acessado 23 Novembro 2021] , pp. 126-135. Disponível em: <https://doi.org/10.1590/S0101-60832007000700016>. Epub 16 Out 2007. ISSN 1806-938X. https://doi.org/10.1590/S0101-60832007000700016. 21. Souza IF, Faciolli LL, Pinto RZA, Padula SAT. Estratégias de enfrentamento utilizadas por pacientes que realizam hemodiálise. $8^{\circ}$ Congresso de Extensão Universitária da UNESP, 2015. ISSN2176-9761. Disponível em: https://repositorio.unesp.br/bitstream/handle/11449/142329/ISSN2176-9761-2015-01-06souza.pdf?sequence=1\&isAllowed=y, acesso em 01 de dezembro de 2021. 